IMAGENS

\title{
Imagens cruzadas: Exército e sertão na Primeira República
}

\author{
Intersecting images: The Army and the \\ hinterlands in the First Republic
}

Rogério Rosa Rodrigues

Professor da Universidade do Estado de Santa Catarina

Av. Madre Benvenuta, 2007

88035-001 - Florianópolis - SC -

Brasil

rogerclio@gmail.com
RODRIGUES, Rogério Rosa. Imagens cruzadas: Exército e sertão na Primeira República. História, Ciências, Saúde - Manguinhos, Rio de Janeiro, v.19, n.4, out.-dez., p.1301-1317.

Resumo

Analisa a proposta político-social do Exército para a nação brasileira na década de 1910. Articula o momento de modernização do Exército com o contexto de avaliação crítica do regime republicano e valorização da corporação militar nos jogos de poder. O método de análise consistiu no cruzamento das fotografias da Guerra do Contestado com os discursos militaristas presentes nos livros escritos por oficiais do Exército, nos artigos publicados na imprensa carioca e nos discursos proferidos por Olavo Bilac em prol do sorteio militar. Foi identificado o desejo do Exército de ligar sertão e litoral, e de adotar a caserna como espaço privilegiado para a formação de cidadãos.

Palavras-chave: Guerra do Contestado; Exército, fotografia de guerra, sertão; Brasil. .

\section{Abstract}

The article analyzes the Army's political and social proposal for the Brazilian nation in the 1910s. It considers the Army's climate of modernization in conjunction with the prevailing context of critical evaluation of the republican regime and greater recognition of the role of the armed forces in power games. The analytical method was to cross-reference photographs from the Contestado campaign with militarist discourses found in books authored by Army officers, in articles published in the Rio de Janeiro press, and in Olavo Bilac's speeches in favor of a draft lottery. It was found that the Army wanted to link the hinterlands to the coast and to adopt the barracks as a prime space for forming citizens.

Keywords: Contestado campaign; Army; war photography; hinterlands; Brazil. 


\section{O Contestado e os militares}

Ao assumir a liderança na repressão ao movimento do Contestado ${ }^{1}$ em agosto de 1914, o Exército brasileiro aproveitou a ocasião para alavancar o projeto institucional de modernização de seus quadros e ao mesmo tempo sua proposta político-social para o desenvolvimento da nação brasileira. À corporação era atribuída a missão de civilizar os sertões e levar o progresso e a civilização aos recônditos do país. Os militaristas acreditavam que a formação dos cidadãos deveria passar pela caserna e que somente uma instituição de abrangência nacional com comando forte seria capaz de formar verdadeiros patriotas e combater o domínio oligárquico, visto como vício a corroer o regime republicano.

O início de 1910 foi um marco importante nesse contexto, uma vez que a campanha presidencial que opôs Rui Barbosa ao oficial do Exército Hermes da Fonseca, dividira as elites políticas. ${ }^{2}$ Outras iniciativas promovidas pelos militares reforçam o argumento de que a revitalização política do Exército não passava apenas pela modernização institucional da corporação, como faz crer José Murilo de Carvalho (1974). As investidas promovidas no interior do país pela Comissão Rondon, a campanha de derrubada de velhas oligarquias estaduais conhecidas como 'política das salvações' e a formação da Liga de Defesa Nacional (LDN) são exemplos plausíveis de que o Exército tinha ambições que ultrapassavam os limites da caserna. Acreditamos que por meio dessas iniciativas, a corporação firmava sua missão político-social e dava contornos a uma proposta para o desenvolvimento da nação.

Nesse cenário, a participação do Exército na repressão aos sertanejos do Contestado assumiu caráter singular. Por meio do exame das estratégias e ações desenvolvidas dentro e fora do campo de batalha no limite do Paraná com Santa Catarina vislumbramos tanto a reforma institucional como o projeto político-social do Exército. No primeiro caso, analisaremos a promoção da tecnologia e das estratégias de guerra efetuadas pelo comandante-geral da operação militar; no segundo, atentaremos para os discursos subjacentes à ação militar. Para dar conta da proposta concentraremos nosso enfoque nas fotografias de guerra. Considerando os critérios de sua fabricação, a lógica da seleção, o diálogo com as demais linguagens e discursos, bem como a política de sua veiculação, entendemos que tais imagens assumem um caráter poderoso de divulgação dos ideais militares.

\section{A fotografia de guerra e o Exército}

Desde a chegada das tropas federais no cenário de guerra, em setembro de 1914, a imprensa brasileira denunciava a possibilidade de se repetir no sul do Brasil o que ocorrera em Canudos. A relação efetuada destacava o despreparo do Exército, a ignorância da população rural e a necessidade de medidas urgentes para pôr fim ao movimento rebelde.

A intervenção federal no Contestado se deu pela solicitação formal dos presidentes de governo dos estados contendores. O fato denuncia o poder da resistência e das reivindicações dos fiéis de João Maria ${ }^{3}$, bem como a incapacidade das forças militares dos estados em reprimir o movimento sertanejo. Os rebeldes lutavam pelo direito de compartilhar suas crenças religiosas, mas também contra o desmando dos coronéis locais e contra os interesses 
capitalistas da Brazil Railway Company e a empresa por ela subsidiada, Lumber and Colonization Company. A primeira ficou responsável pela construção da estrada de ferro que promoveu a ligação entre São Paulo e Rio Grande do Sul, a segunda pela colonização das terras e exploração da madeira na região (Monteiro, 1974; Diacon, 1991).

No comando das operações repressivas estava Fernando Setembrino de Carvalho, militar que estivera à frente da intervenção federal no Ceará no primeiro semestre de $1914 .{ }^{4}$ Carvalho levou para o cenário de guerra os regimentos mais bem treinados do país, tecnologia bélica de ponta e estratégia militar inspirada nas mais modernas instruções da Europa (Rodrigues, 2008). A experiência lhe mostrara que, além da força, uma guerra também se vencia pelo discurso. Por isso permitiu que oficiais ilustrados seguissem para o campo de batalha com a missão de imortalizar os feitos militares em publicações de caráter científico. ${ }^{5}$

No teatro de guerra, os historiadores de farda ${ }^{6}$ produziram e recolheram farta documentação sobre a atuação do Exército, estabeleceram comparações entre Canudos e o Contestado e buscaram aproximar a narrativa dos feitos militares nesse conflito com a efetuada em Os sertões. O objetivo maior desses oficiais ilustrados era redimir o Exército da imagem negativa que vigorava sobre sua ação no sertão baiano. Tal imagem era tributária do sucesso de Os sertões no meio intelectual; por isso o empenho dos historiadores de farda em ultrapassar o livro máximo de Euclides da Cunha. ${ }^{7}$

Dermeval Peixoto é o que melhor dialoga com a arquitetura estético-política de Os sertões. Em 1916 lançou o primeiro de três volumes sobre a atuação militar no Contestado. Eis como o historiador de farda descreve os fiéis de João Maria e os jagunços a serviço do Exército:

Em Poço Preto, uma prole de cerca de dez infelizes criaturas, aleijadas, deformadas e carcomidos de lepra e de 'bicho de pé' os membros, os corpos desnudos, foi ter às barracas da força do Exército. Mas, impiedosos desta vez, os soldados que acampavam junto ao coronel Fabrício não se condoeram do triste desígnio dos leprosos desgraçados. Ninguém os queria por perto, ninguém estendeu a mão com uma bolacha seca para os aleijadinhos esqueléticos. Por fim, ao atravessarem numa canoa as correntezas do Iguaçu, as criaturas asquerosas deixaram de sofrer para sempre. A canoa virou... e Canudos se repetia em todos os seus aspectos multiformes (Peixoto, 1995, v.1, p.76)

A crítica de Peixoto faz referência sutil a Euclides ao repetir as denúncias sobre o tratamento que as forças legais conferiam aos prisioneiros de guerra: a degola era o destino dos líderes rebeldes. Em sua pena, a barbaridade é sugerida na menção à canoa virada no rio Iguaçu. O militar não atribui ao Exército a responsabilidade pela morte. Ela recai exclusivamente na força civil, ou seja, nos chamados vaqueanos.

Ao fim do terceiro volume da epopeia militar de Peixoto, Euclides novamente se faz presente em parágrafo de arremate das ideias. O historiador de farda narra a tomada de uma das maiores vilas sertanejas do Contestado, Santa Maria: "quem mesmo pernoitou uma ou duas noites naquele antro não terá agora na imaginação as exatas proporções do local fatídico. Santa Maria continua sendo uma interrogação. Nenhuma fotografia!!!" (Peixoto, 1995, v.3, p.157).

Se não temos imagens fotográficas da comunidade que chegou a abrigar dez mil pessoas nos limites do Paraná com Santa Catarina, o mesmo não pode ser dito em relação à 
atuação militar nesse conflito. Atualmente, sob a guarda do Arquivo do Exército no Rio de Janeiro (AHEx) é possível encontrar um álbum da guerra contendo 87 fotografias. ${ }^{8}$ As imagens, feitas no campo de batalha sob a encomenda do comandante-geral das operações militares, tinham como objetivo imediato registrar o preparo técnico e disciplinar do Exército brasileiro nos sertões sulinos. Com essa iniciativa o general repetia prática bem-sucedida nas forças armadas ao incluir a tecnologia fotográfica no moderno arsenal militar a sua disposição. As imagens técnicas (Flusser, 2002) produzidas no campo de batalha, além de assumirem o estatuto de registro e de provas, cumpriram a função de anunciar o projeto que a corporação possuía para a nação.

A maior parte dessas fotografias é de autoria de Claro Jansson, sueco radicado na região contestada no final do século XIX (Moretti, 2008). Ele ficou conhecido pela alta cúpula militar em função da imagem que fez do corpo do capitão João Gualberto, morto no combate do Irani em 1912. Hermes da Fonseca lhe presenteou com a patente de oficial da Guarda Nacional (D'Alessio, 2003), e Setembrino de Carvalho, com a primazia no registro dos feitos militares na guerra travada contra os sertanejos do Contestado (Rodrigues, 2008).

Desde a Guerra do Paraguai, a fotografia foi usada com destaque entre os arsenais bélicos (Andrade, 2002). Em Canudos, a contratação de um fotógrafo expedicionário, Flávio de Barros, foi fundamental para encenar a vitória do Exército contra a comunidade conselheirista (Mauad, 1993). O mesmo pode ser dito sobre o papel da máquina fotográfica nas operações levadas a cabo por Cândido Rondon nos recônditos do país (Tacca, 2001; Maciel, 1998).

De acordo com Flusser (2002) o sucesso das imagens técnicas se deve em grande parte à operação mecânica que envolve a construção da imagem. Para Sontag (2004, p.174), "a fotografia restabelece a mais primitiva forma de relação - a identidade parcial entre imagem e objeto ... A noção primitiva de eficácia das imagens supõe que as imagens possuem o predicado das coisas reais".

Se Flusser tem razão ao ressaltar o papel da máquina na operação fotográfica e Sontag em destacar o efeito da imagem sobre o outro, queremos chamar a atenção para a ação do sujeito por trás da câmera, nesse caso, o fotógrafo e o comandante das operações militares. Como contratante, o Exército dita as regras e seleciona o que merece ser preservado e o que deve ser excluído.

No álbum do Contestado o que se apresenta é um Exército totalmente disciplinado e bem equipado. Se inserimos essas imagens no contexto de (a) reformas institucionais por que passava a corporação na época; (b) críticas ao regime republicano; e (c) emergência de projetos nacionais, elas ganham significado que ultrapassa aquilo que é apresentado. Em outras palavras, se as fotografias do Contestado reunidas no álbum militar foram usadas para reforçar o discurso oficial promovido pelo Exército, também desempenharam o papel de construir uma narrativa que ia além da situação representada.

Tais imagens anunciavam à sociedade brasileira o projeto promovido pelo Exército de intervenção civilizadora no interior do país. Interior que também era representado como bárbaro e, de modo paradoxal, potencialmente propício ao desenvolvimento da nação. Tais representações não foram criadas nem tampouco compartilhadas apenas por oficiais militares. Euclides da Cunha seria um de seus principais formuladores. De acordo com 
Nísia Trindade Lima (1999, p.61), “As perspectivas que valorizam positivamente ou abordam de forma ambivalente aquele que é visto comumente como o polo do atraso e da resistência ao progresso veem o sertão como a possibilidade do desenvolvimento de uma autêntica consciência nacional". Em sintonia com essa visão Peixoto (1995) chegou a lamentar que a politicagem reinante na divisa de Santa Catarina com o Paraná ceifasse tantos braços para o labor da terra do campo e para o desenvolvimento da nação.

Segundo Lima (1999), essas ideias sobre o sertão brasileiro impulsionaram as 'missões civilizatórias' intensificadas a partir de 1910, dentre as quais destaca as promovidas pelo Instituto Oswaldo Cruz. Para a pesquisadora, as missões tiveram como consequência a incorporação definitiva do sertão e do sertanejo na agenda de discussão sobre a ideia de nação e de raça no Brasil. Se os cientistas, denominados por Trindade médicos-etnógrafos, articularam doença e nacionalidade, Olavo Bilac, como porta-voz da LDN e em sintonia com os ideais defendidos pelos militares modernizadores, trabalhou com a ideia de Exército e nacionalidade.

A defesa nacional, na visão de Bilac (1965), passava pela educação, que deveria tomar como modelo o ambiente militar. Em suas palavras, "a caserna é um filtro admirável, em que os homens se depuram e apuram: dela sairiam conscientes, dignos, brasileiros" (p.27). A construção de uma cidadania almejada para uma república sem cidadãos, passaria, portanto, conforme o discurso de Bilac, pela formação militar.

Para Antonio Dimas (2006), o mergulho de Bilac no projeto nacionalista tem como marco 1908, momento em que o príncipe dos poetas abandonou o ofício de jornalista:

[Em 1907] Bilac já estava prestes a renunciar à crônica semanal, tanto na Gazeta de Notícias como no Correio Paulistano, jornais que acolheram suas últimas colaborações sistemáticas. Devagar, devagar, a partir de 1908, o cronista ia despedindo-se das redações para dedicarse de corpo e alma à campanha pela defesa do território nacional e pelo serviço militar obrigatório, assunto dos historiadores. Por causa das duas campanhas, aquele que começara poeta e continuaria jornalista transforma-se agora em líder cívico e viaja, em pregação oficial, pelo Sul do país, visitando Porto Alegre, Curitiba e São Paulo, onde foi recebido de forma inflamada, já nos últimos anos de sua vida, em 1916 (p.60).

Lucia Lippi Oliveira (1990, p.120) constata que desde sua atuação na revista Kosmos (Rio de Janeiro), em 1905, "Bilac já defendia a educação primária e o serviço militar obrigatórios". Se esses primeiros contatos são apenas indícios da parceria que Bilac estabeleceria com os militares e seus ideais antes de mergulhar na proposta da LDN, o discurso proferido aos estudantes do curso de direito, em 1915, na cidade de São Paulo, já anunciava a mão estendida para o trabalho em conjunto com o Exército:

Há sete anos, houve um rebate ansioso e febril. Na tribuna e na imprensa, vibrou um alto chamamento, um toque de alarma a todas as energias adormecidas. E uma lei apontou à nossa esperança o entreluzir de uma promessa de salvação: a lei do sorteio militar, se não a providência completa do serviço militar obrigatório, ao menos um ensaio salutar, o primeiro passo para convalescença e para a cura. Então, como ainda hoje, eu considerava que era esse o único providencial remédio para o nosso definhamento (Bilac, 1965, p.26).

O poeta concluiu sua conferência aos jovens estudantes de direito de São Paulo com empolgação: 
Desta velha casa, de entre estes sagrados muros, que esplendem de tradições venerandas, deste quase secular viveiro de tribunos e de poetas - daqui saíram, em rajadas de heroísmo, em ímpetos de entusiasmo, as duas campanhas gloriosas, que foram coroadas pela vitória da Abolição e da República. Estruja de novo a casa! Estremeçam de novo os muros! E de novo palpite e ressoe o aviário canoro, cheio de hinos de combate de gorjeios de bondade! Inaugurai, moços de São Paulo, a nova campanha! (p.28).

Todo esse desempenho culminaria na formação da LDN, inaugurada nas dependências da Biblioteca Nacional, no Rio de Janeiro, no dia 7 de setembro de 1916. No discurso de abertura, Bilac (1965, p.82) expôs o objetivo da nova organização: "Estimular o patriotismo consciente e coesivo, propagar a instrução primária, profissional militar e cívica; e defender, com a disciplina, o trabalho; com a força, a paz, com a consciência, a liberdade; e, com o culto do heroísmo, a dignificação da nossa história e a preparação do nosso porvir".

Nessa ocasião, definiu-se o Diretório Central da Liga, que reuniu alguns dos mais significativos representantes da elite política e econômica do país. Leila Capella (1985, p.235-236) chama a atenção para os nomes e posição dos presentes: havia ministros de Estado, como o almirante Alexandrino de Alencar (Fazenda), o general José Caetano de Faria (Guerra), Pandiá Calógeras (Fazenda); deputados; representantes da indústria, comércio e agricultura; magistrados, como Pedro Lessa, na época ministro do Supremo Tribunal Federal; representantes do mundo acadêmico, como o conde Afonso Celso, que presidia o Instituto Histórico e Geográfico do Brasil, e o diretor do Instituto de Manguinhos, Oswaldo Cruz; autoridades militares; dirigentes esportivos, além do consultor jurídico do Ministério das Relações Exteriores, Clóvis Bevilacqua, Carlos de Laet, o presidente da Associação Brasileira de Imprensa, Raul Pederneiras, e o monsenhor Vicente Lustosa de Lima, do cabido metropolitano. ${ }^{9}$

Como pode ser observado na composição da LDN, o projeto militar era abraçado por parcela considerável de intelectuais brasileiros. Embora oficializada, em 1916, a missão militar defendida pela LDN já fora anunciada anos antes. Ela coincide com a aprovação da lei do sorteio militar, em 1908, mas se intensifica em 1914-1915, em função da Primeira Guerra Mundial e com a intervenção do Exército no Contestado. Esse conflito permitia aos construtores da missão militar do Exército recuperar aquilo que a corporação arvorava como sua vocação: promover o desenvolvimento do país por meio de uma política centralizadora, unir sertão e litoral e levar a civilização aos recônditos do país.

Nesse contexto, a ideia de civilizar aparecia como estratégia fundamental para solucionar os problemas de uma nação sem cidadãos, vitimada pela miséria e pela ignorância, além de viciada pelo domínio dos coronéis. As fotografias de guerra amplamente veiculadas na imprensa da época assumiam papel primordial na divulgação dessas ideias.

Nas fotografias presentes no álbum militar, há destaque para o cenário natural, representado como terra abandonada, selvagem. Poder-se-ia argumentar que parte da região era realmente inóspita, totalmente tomada pela vegetação; no entanto, havia também vilas e municípios densamente povoados, como União da Vitória ou mesmo o arraial de Santa Maria com seus dez mil habitantes.

Apesar disso, predominam fotografias do Exército em marcha, como a romper as dificuldades naturais impostas pela natureza (Figura 1). Observemos como a tropa é 


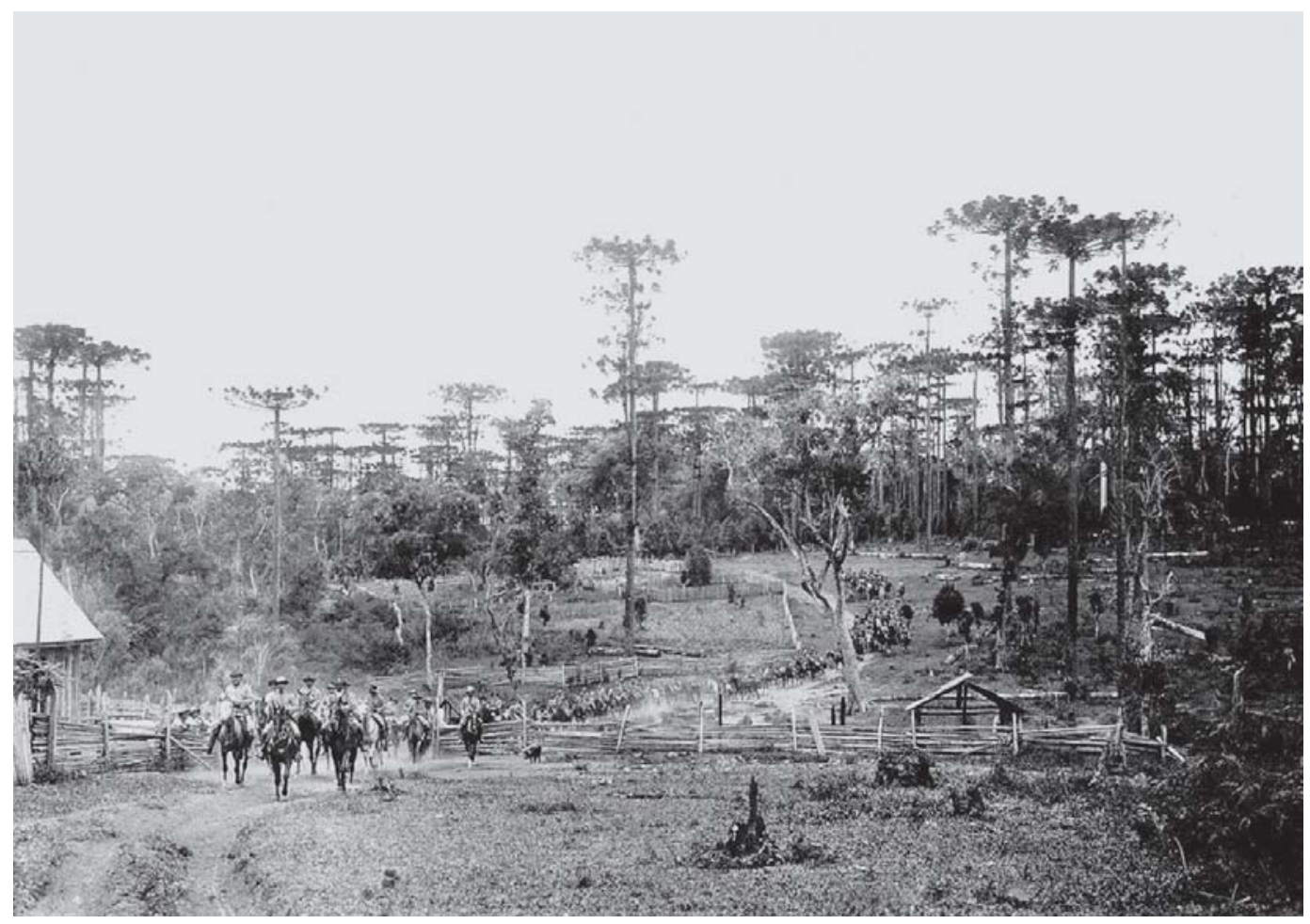

Figura 1: "General Setembrino de Carvalho, chefe das tropas governamentais, e sua escolta em marcha a cavalo pelo sertão do Contestado" (Álbum..., imagem 8, 1914-1915)

totalmente emoldurada pelo espaço físico. É o cenário do sertão, conforme representação da época, que domina o espaço fotográfico. Nessa fotografia como em outras incorporadas ao álbum da guerra, o Exército aparece repetidas vezes como desbravador, imerso em zona perigosa, alvo fácil dos ataques sertanejos. Em sintonia com a atuação da Comissão Rondon, com os discursos promovidos pelos historiadores de farda e pela LDN, essas imagens colocam os soldados e, por conseguinte, a corporação que os abriga como desbravadores.

Para o discurso militar, dominar o conflito passava necessariamente pelo reconhecimento e domínio da natureza. Não foi por acaso que uma das ações implementadas pelas forças repressoras do movimento do Contestado foi elaborar a cartografia da região (Rodrigues, 2008). Para tanto, os oficiais tiveram que percorrer o território, estudar a hidrografia e a geologia do planalto catarinense, além de recorrer aos saberes da população local para registrar os pontos de difícil acesso. Os mapas resultantes desse levantamento tinham dupla função: preparar estratégia de guerra eficaz e incorporar a região ao território nacional. Nesse, como nos demais casos em que se ressalta a presença do Exército, no interior do país, os discursos se casam: o ambiente natural e suas potencialidades precisam ser dominados para o bem do progresso.

Ainda na lógica da relação natureza/sertão/barbárie, encontramos afinidades em outros discursos. Nos livros publicados pelos historiadores de farda, as vantagens militares dos rebeldes do Contestado contra uma força tecnicamente mais bem equipada eram atribuídas ao conhecimento que os sertanejos tinham da região. 
De acordo com os oficiais ilustrados, a vegetação, a oscilação climática e os declives do planalto catarinense, totalmente desconhecidos pelos militares, facilitavam as emboscadas dos revoltosos. Ao traçar uma comparação entre Canudos e o Contestado José Pinto Soares (1920, p.126) registrou ${ }^{10}$ : "No Contestado, porém, o inimigo era um misto de fanáticos, bandidos e exploradores de todos os matizes. Não havia, portanto, sincera uniformidade na flâmula de combate desfraldada. Preferia a luta traiçoeira das emboscadas ao abrigo da intérmina e espessa mataria; a caçada, covarde e vil, por detrás do pau, à nobre luta das clareiras a peito descoberto, enfim".

$\mathrm{Na}$ fotografia de guerra, a retórica do Exército engolido pelo sertão se repete. Apesar disso, as tropas aparecem em marcha, impondo-se às dificuldades naturais, como a deficiência das estradas e do clima (Figura 2). Mesmo nas imagens que registram as manobras militares (Figura 3), evidenciando a disciplina e o preparo bélico, o que vemos é a natureza a emoldurar o cenário (Figura 4).

Como já dito, se nas imagens fotográficas o sertão sufoca as tropas, nem por isso impede o Exército de desbravá-lo, civilizá-lo. No álbum, algumas fotografias encenam os soldados instalando fios telegráficos, dando a entender a missão da força terrestre de ligar o sertão ao litoral (Figuras 5 e 6).

Telégrafo e telefonia são fundamentais para agilizar a comunicação e, portanto, essenciais para a estratégia militar, mas também representam os ideais de progresso e de civilização. Imagens como essas tanto encenam o suposto boicote dos sertanejos à chegada da modernidade quanto apresentam o Exército como o propagador dessa mesma modernidade - tarefa atribuída ao Estado, mas que a corporação abraça para si.

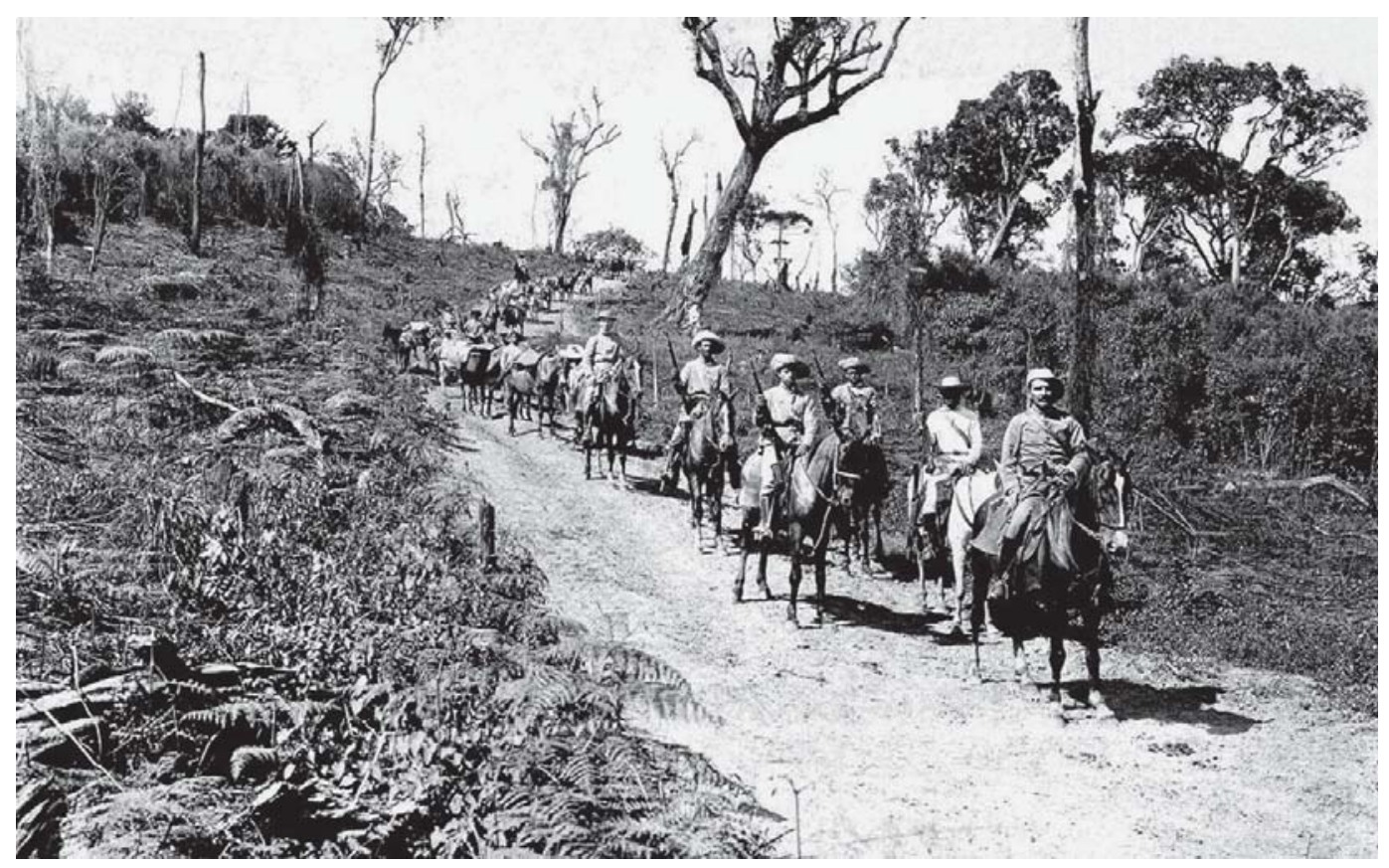

Figura 2: "Pelotão de transporte de gêneros no sertão catarinense, por ocasião da Campanha do Contestado" (Álbum..., imagem 29, 1914-1915) 


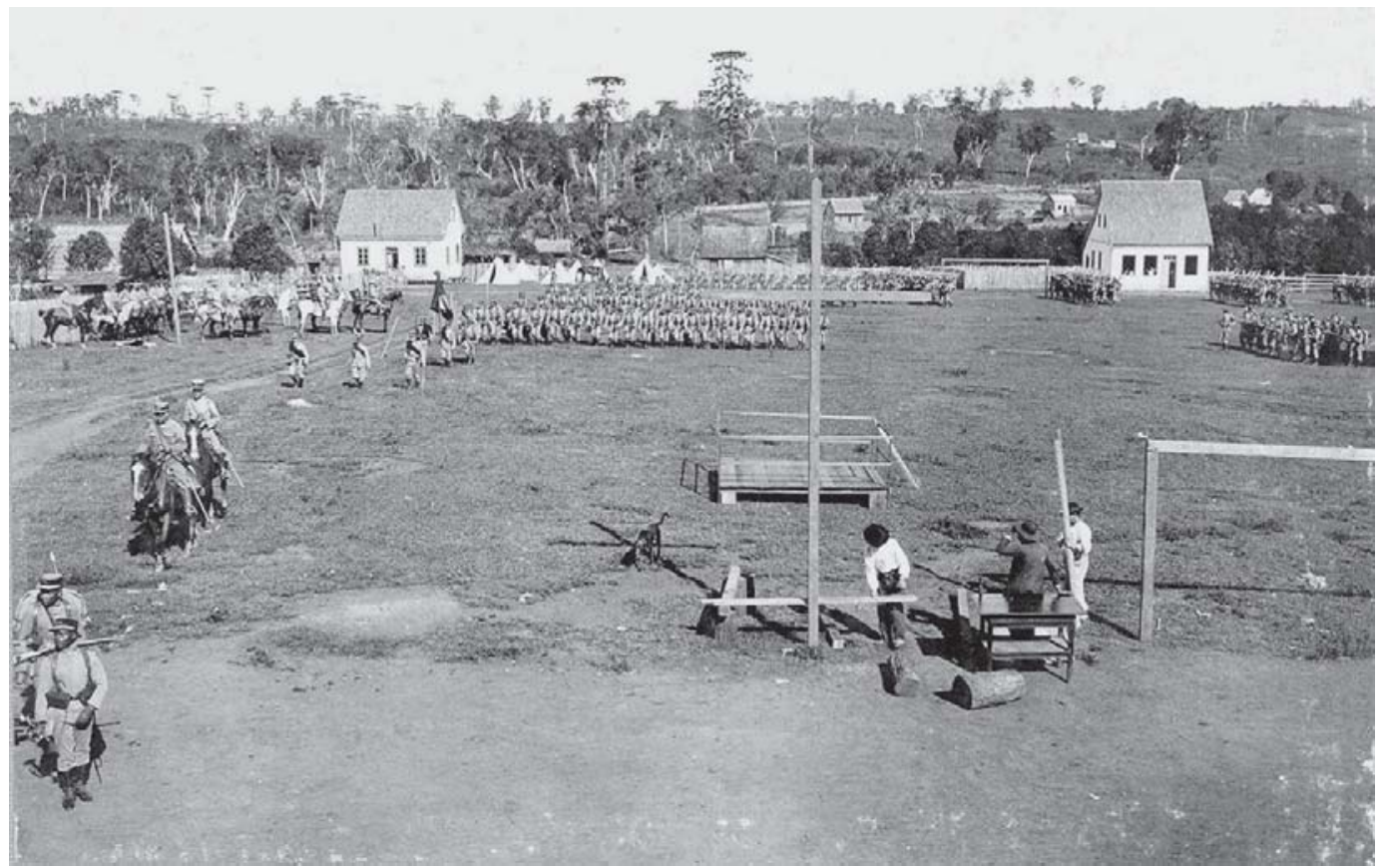

Figura 3: "Revista feita pelo General Setembrino de Carvalho, chefe das tropas governamentais, ao Quinquagésimo sexto Batalhão de Caçadores sob o comando do Coronel Onofre Ribeiro em Canoinhas, SC" (Álbum..., imagem 21, 1914-1915)

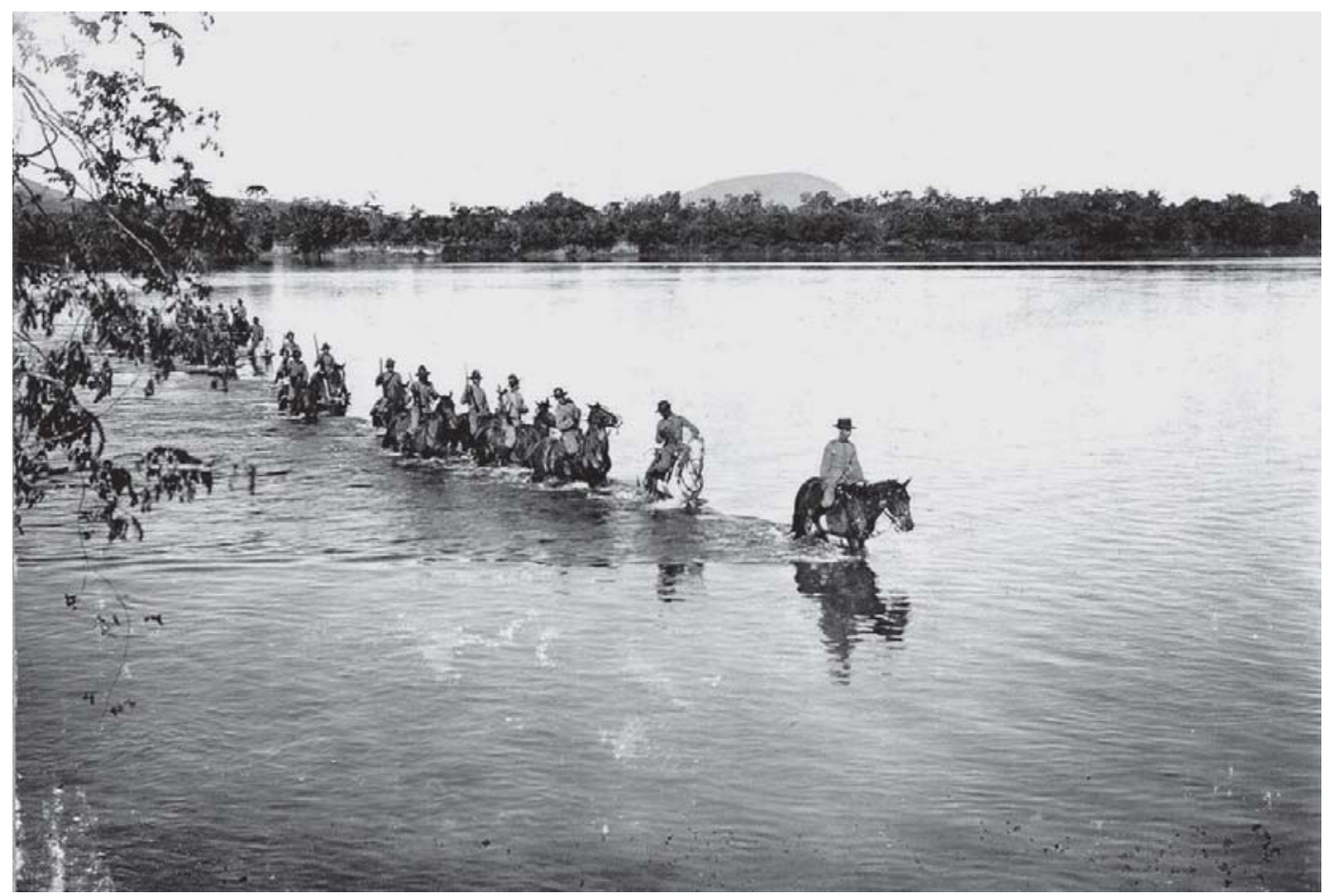

Figura 4: "Travessia do rio Iguassu pelo piquete de Cavalaria do Regimento de Segurança do Paraná que acompanhou a escolta do General Setembrino de Carvalho" (Álbum..., imagem 58, 1914-1915) 


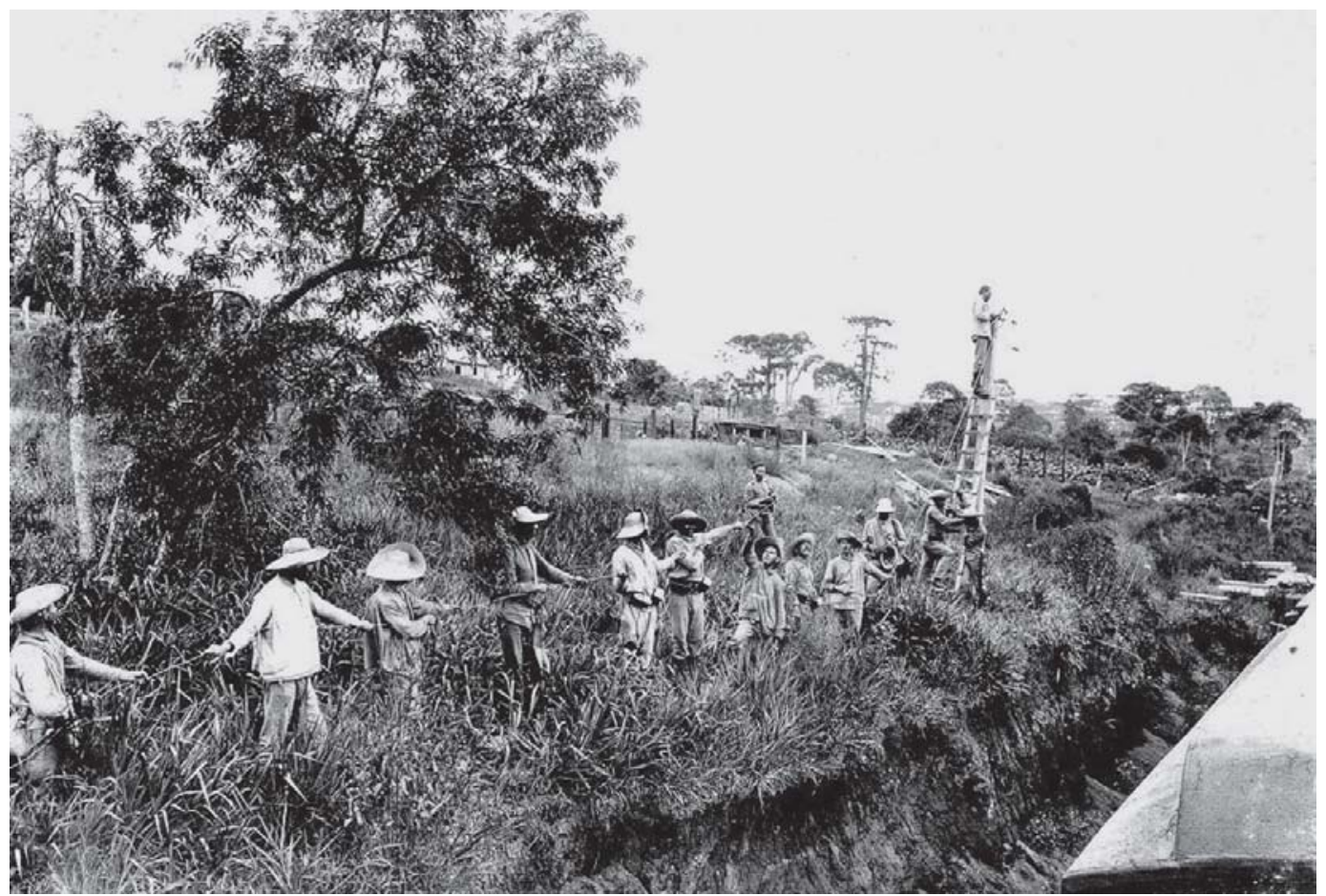

Figura 5: "Integrantes da Companhia de Engenheiros do Segundo Batalhão realizando tarefa de restabelecimento da linha telegráfica da Estrada de Ferro entre Canoinhas (SC) e União da Vitória (PR), interrompido pela ação dos rebeldes" (Álbum..., imagem 51, 1914-1915)

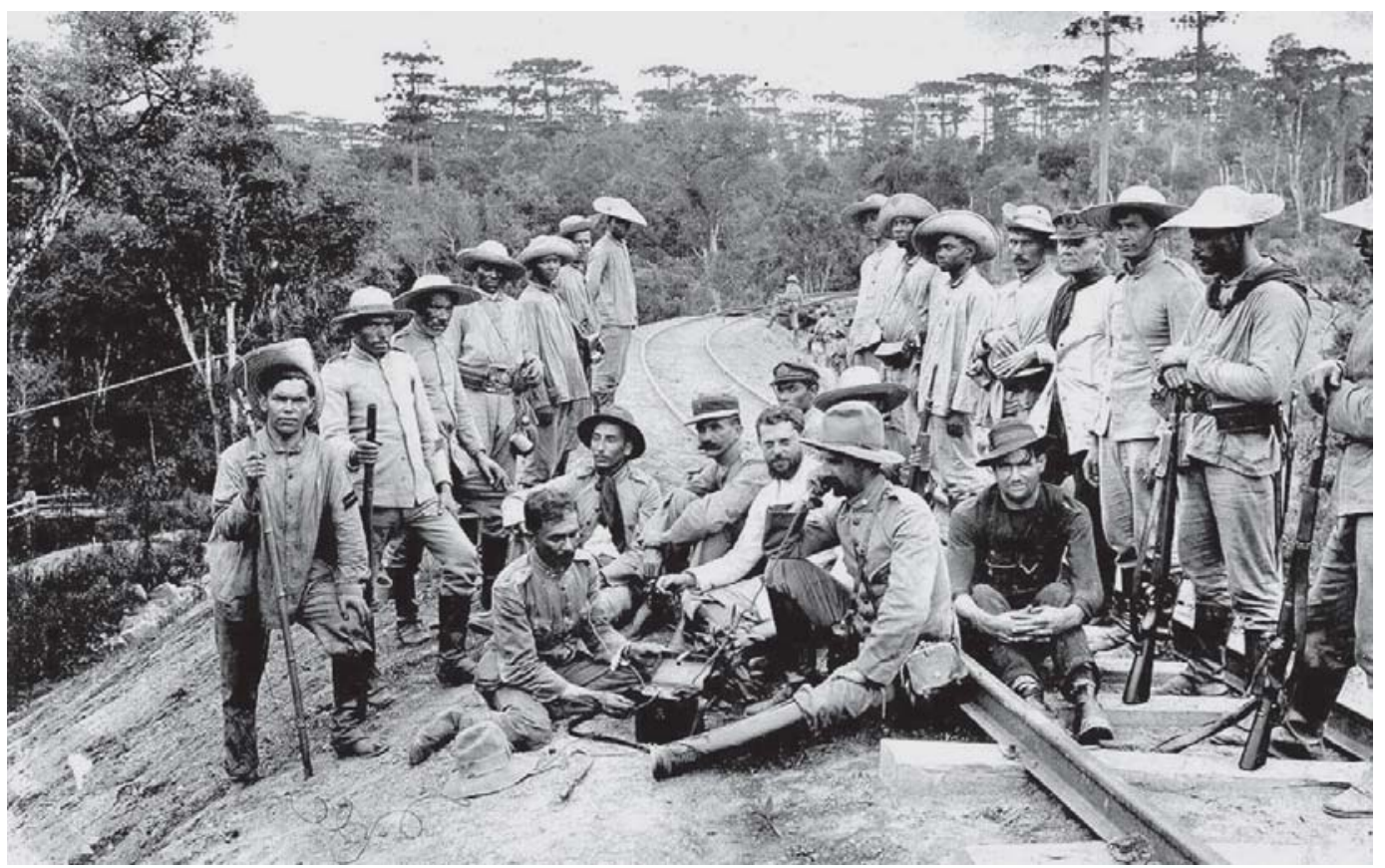

Figura 6: "Integrantes da Companhia de Engenheiros do Segundo Batalhão reunidos junto ao posto telefônico de campanha" (Álbum..., imagem 52, 1914-1915) 
Nas fotografias da Guerra do Contestado o projeto nacional do Exército é encenado por meio de outros cartões-postais da modernidade: a estrada de ferro e as pontes. A estrada de ferro era um dos símbolos máximos do desenvolvimento capitalista no início do século XX. Na região, a Brazil Railway Company era responsável por ligar São Paulo ao Rio Grande do Sul. Sua presença alterou profundamente as relações sociais e comerciais na região ao expulsar posseiros de suas terras, capitalizar as propriedades e instaurar uma empresa colonizadora de terras e uma grande serraria no local (Silva, 1983). Em função disso, tornou-se um dos alvos de ataque dos sertanejos.

Em termos estratégicos, a estrada de ferro facilitava o deslocamento rápido de homens e munições; logo, contribuía para aquilo que o Exército assumia como uma de suas principais atribuições: a defesa nacional. Nesse sentido, era fundamental atrelar a corporação aos interesses da empresa norte-americana responsável pela construção da estrada de ferro, assim como ressaltar a suposta barbaridade dos sertanejos ao registrar os escombros de parte dos trilhos ou de pontes que atravessavam a região.

No álbum aparecem três fotografias com escombros de uma ponte (Figura 7): artefato de grande significado para os ideais de civilização do período. Além de propiciar o

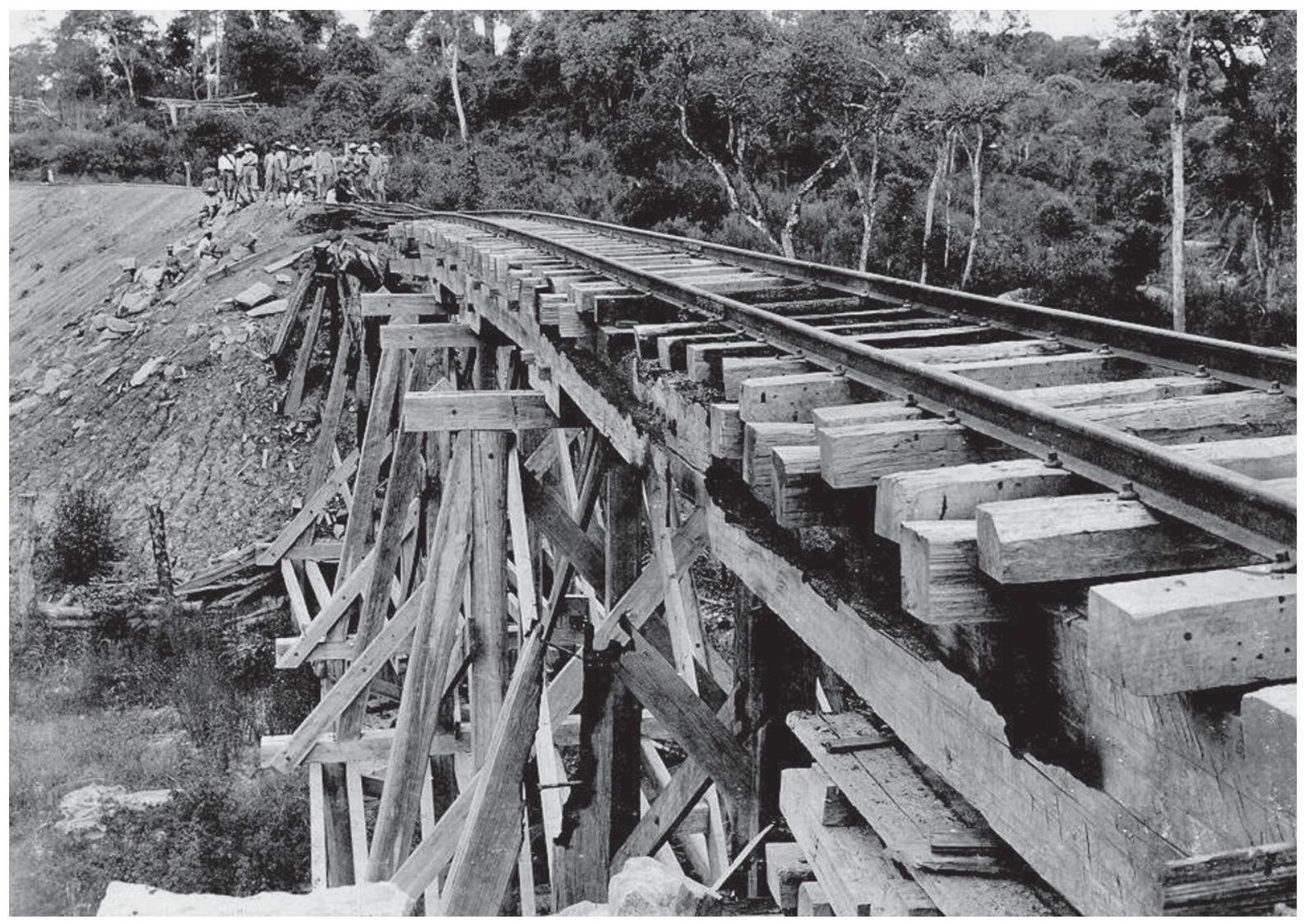

Figura 7: "Aspecto da ponte provisória da Estrada de Ferro São Francisco, incendiada pelos rebeldes do Contestado, vendo-se ao fundo elementos da Companhia de Engenharia do Segundo Batalhão fazendo o reconhecimento da área" (Álbum..., imagem 49, 1914-1915) 
deslocamento de pessoas e de mercadorias, a ponte trazia em sua própria materialidade os elementos do desenvolvimento, tais como o labor intelectual para sua concepção por meio da tecnologia utilizada em sua construção, a matéria-prima que ia da madeira ao aço, sem contar a mão de obra de profissionais que, no Brasil, era formada nas escolas militares: os engenheiros. Dessa forma, as fotografias de pontes destruídas estão carregadas de significados. Uma interpretação possível é que os oficiais do Exército estavam restaurando aquilo que os sertanejos haviam destruído, ou seja, o progresso.

Em todos esses casos temos uma retórica que coloca o Exército ao lado do progresso e da civilização, e os sertanejos atrelados à ideia de barbárie e ignorância. Deslocadas dos livros, relatórios e álbuns fotográficos do Exército, as fotografias da Guerra do Contestado disputaram espaço na imprensa nacional com as imagens da Primeira Guerra Mundial. Uma vez veiculadas nos periódicos, passaram a se articular com os discursos patrióticos de Bilac e dos historiadores de farda e a definir o papel político e social do Exército brasileiro no desacreditado regime republicano.

\section{As fotografias de guerra na imprensa}

No momento da intervenção federal no Contestado foi conflagrada a Primeira Guerra Mundial na Europa, episódio que passou a ocupar todas as atenções da imprensa. Os periódicos do Brasil dedicavam-se quase integralmente à edição de matérias e fotos da guerra europeia. As informações sobre a Guerra do Contestado ganhavam notas perdidas em páginas finais ou, quando muito, mereciam uma coluna fixa sob títulos como "Os episódios no Sul" ou "Os fanáticos do Contestado". Mesmo nos jornais dos estados beligerantes - Paraná e Santa Catarina -, as matérias sobre a rebelião sertaneja ficavam em segundo plano. Até mesmo a nacionalista revista militar, A Defesa Nacional, lançada, em 1913, concentrou suas atenções na guerra mundial.

A prestigiada revista Fon-Fon foi um dos poucos periódicos a dedicar espaço significativo à divulgação das fotografias do Contestado. O episódio não ocupou as primeiras páginas da revista, mas ganhou coluna cativa entre novembro de 1914 e maio de 1915. O título da coluna era "Fon-Fon! no Contestado". As fotografias apareciam cobrindo toda a página, geralmente com uma legenda identificando os personagens, mas nunca com o nome do fotógrafo. Algumas imagens eram encaminhadas pelo próprio retratado, possivelmente na ânsia de ter sua figura reconhecida socialmente, por meio de um ato de bravura. Henrique Wolland, por exemplo, aparece nas páginas da Fon-Fon (Figura 8). Ele se aliou às forças repressoras após ter participado ativamente do movimento rebelde. O diretor da Lumber and Colonization Company também está entre os popularizados na imprensa (Figura 9), assim como muitos oficiais anônimos.

Além das fotografias encaminhadas por indivíduos, havia as de caráter mais institucional (Figura 10) e que, ao que tudo indica, foram enviadas pelo próprio comando militar. A diferença entre elas reside no fato de as imagens institucionais apresentarem o Exército como força coletiva, com destaque para os equipamentos bélicos e para ações em meio ao sertão brasileiro. 


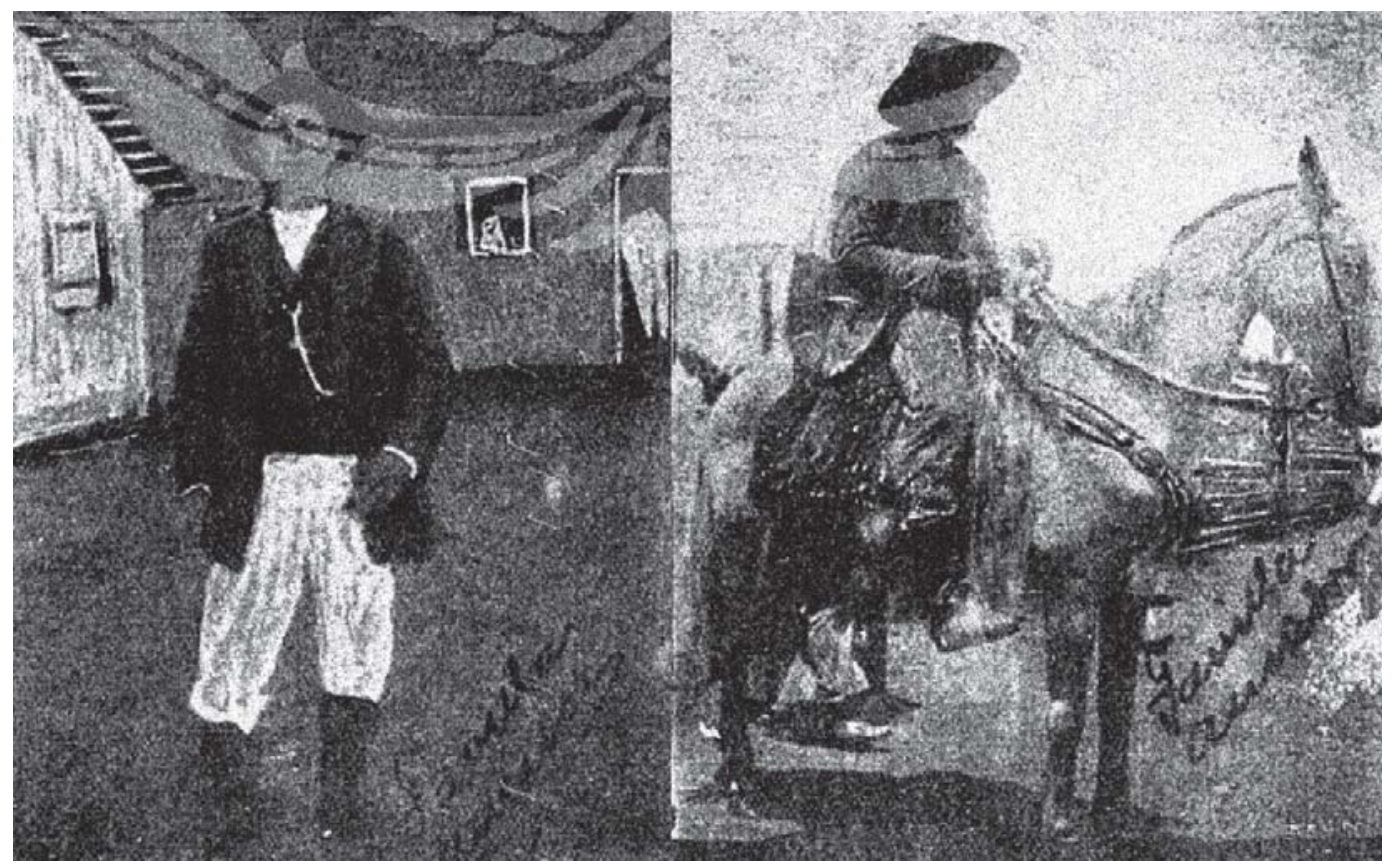

Figura 8: "Fon-Fon! No Contestado. Dois chefes de bandos: À esquerda Henrique Wolland, vulgo Alemãozinho, chefe de um terrível grupo de bandoleiros, residente em Joinville, SC - À direita Zé Caboclo, também chefe de um grupo de Bandoleiro". (Dous chefes..., 29 jan. 1915, p.33)

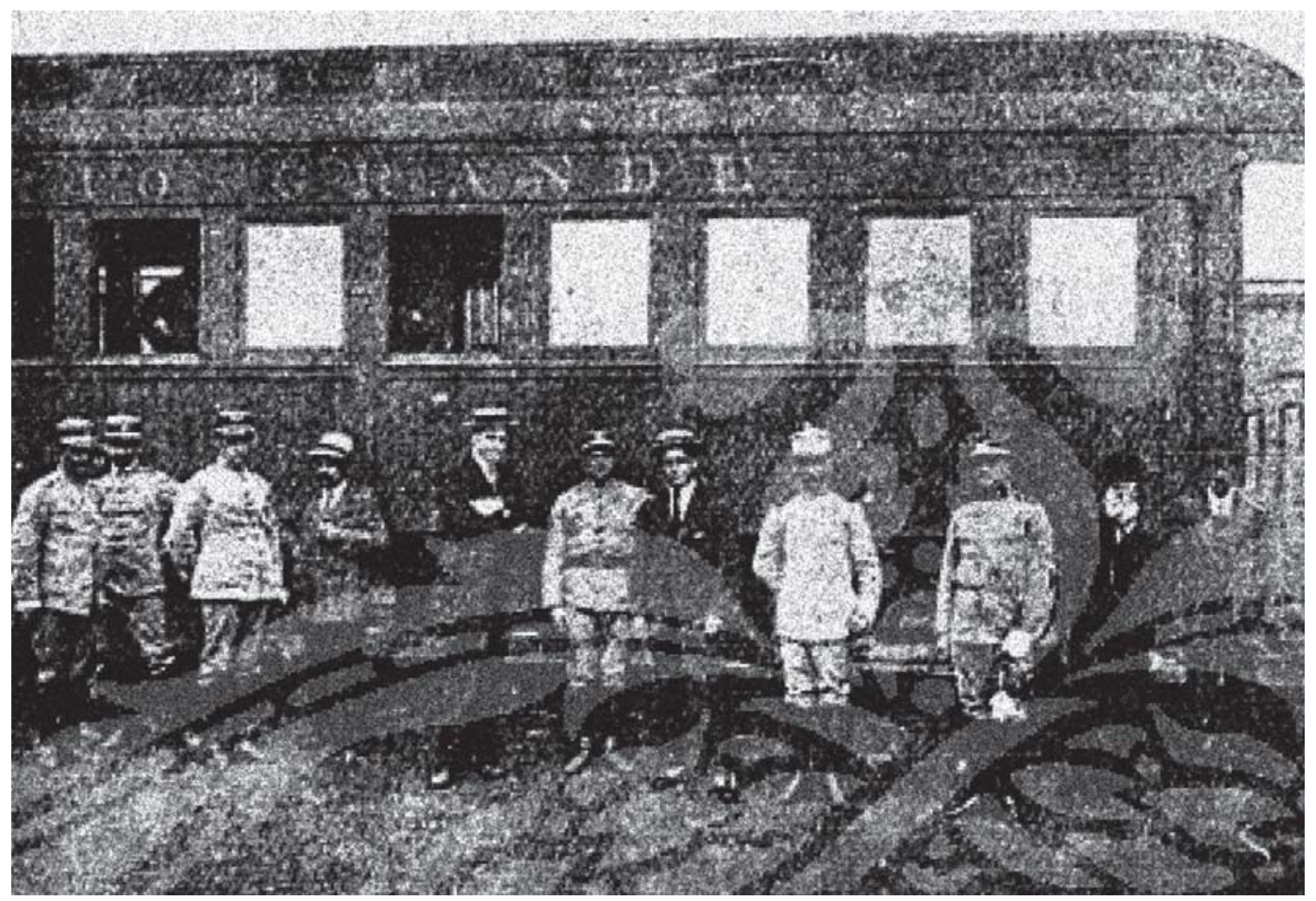

Figura 9: "Fon-Fon! No Contestado. O Sr. General Setembrino visita Três Barras no Paraná, zona conflagrada pelos fanáticos" (Fon-Fon..., 13 fev. 1915, p.48) 

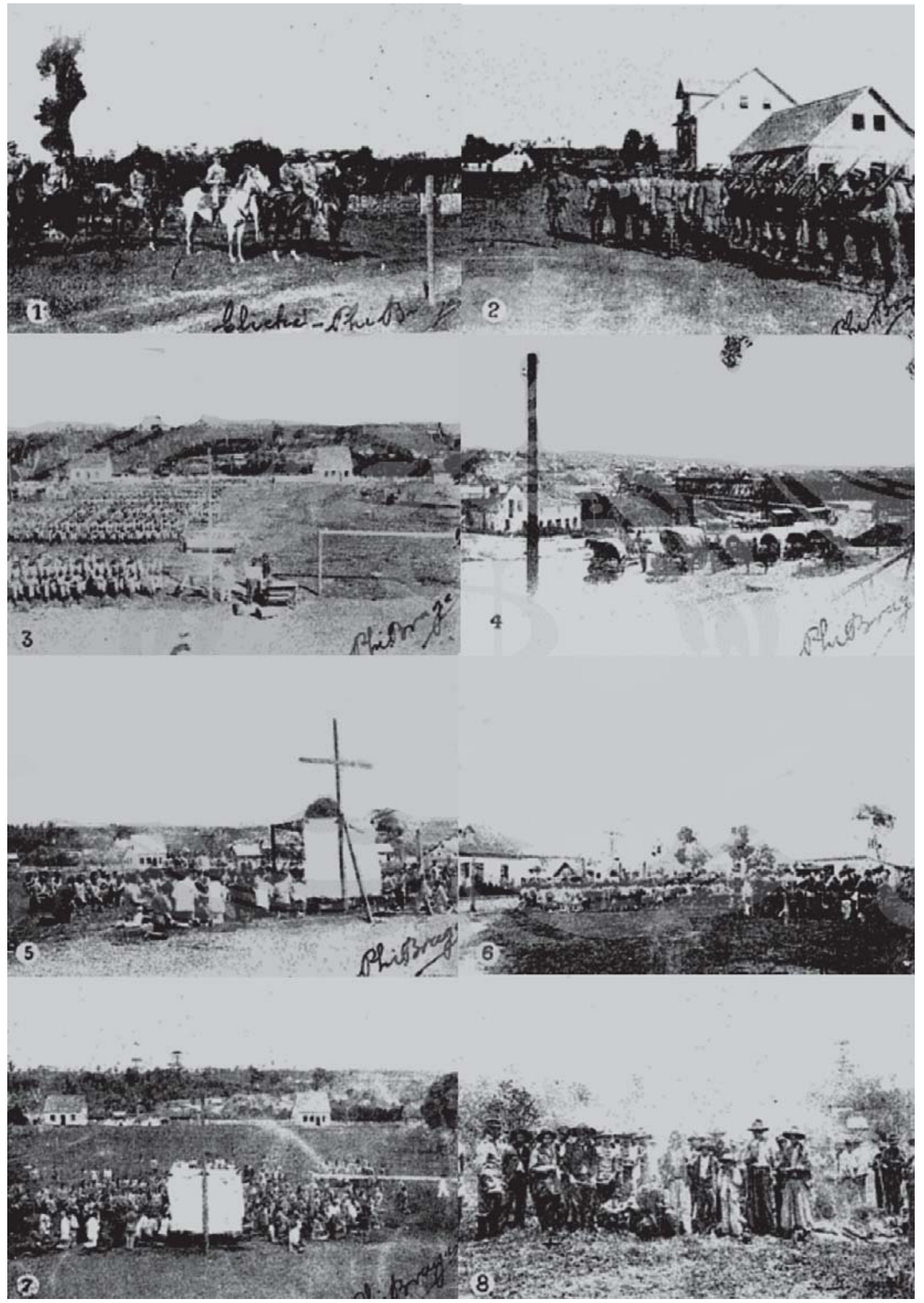

Figura 10: "Fon-Fon! No Contestado. Diversos Aspectos" (Diversos aspectos, 6 fev. 1915, p.22) 


\section{Considerações finais}

Os critérios de seleção das fotografias de guerra publicadas na Fon-Fon atendiam perfeitamente aos interesses militares, como registrar o investimento do Exército em novas tecnologias bélicas. Isso era fundamental para minimizar a imagem que se tinha das corporações militares, como espaços que abrigavam bandidos, sodomitas e práticas de castigo corporal herdadas do período da escravidão (Beattie, 2009).

A lógica das fotografias dava a entender que o Exército estava técnica e disciplinarmente preparado para receber os jovens brasileiros que seriam recrutados pelo sistema do sorteio. O esforço ganha sentido quando verificamos que o sorteio militar aprovado em lei, em 1908, ainda não havia sido implementado por falta de força política e apoio da sociedade (Rodrigues, 2008). As imagens coincidem com a febre dos projetos nacionais que tinham o homem do campo como objeto central. A LDN abraçou a causa militar e dela fez missão.

Nesse empreendimento vale destacar o entrelaçamento das linguagens. Seja o texto escrito na imprensa ou nos livros publicados pelos historiadores de farda, seja a fotografia ou a charge, a ideia de sertão como sinônimo de ignorância e de barbaridade predominava. Ao colocar o Exército atuando em ações repressivas apresentadas como civilizatórias no interior do país, a fotografia de guerra mostrava a corporação como a força capaz de restaurar os 'verdadeiros' ideais republicanos, ou seja, a divulgação dessas imagens fortalecia a ideia de um Exército portador de missão civilizatória, pronto para restaurar a ordem, levar o progresso, defender a nação e unir o sertão ao litoral.

\section{NOTAS}

${ }^{1}$ A Guerra do Contestado tem como marco oficial os anos 1912 e 1916, ainda que a intervenção federal e a consequente declaração de "estado de guerra" na região limítrofe do Paraná com Santa Catarina só tenha ocorrido em agosto de 1914. O envio de tropas federais ao Contestado marcou nova fase na repressão ao conflito e um momento importante de atuação do Exército brasileiro na repressão aos movimentos sociais do campo. A relação da intervenção federal com a modernização militar foi analisada em minha tese de doutorado defendida no Programa de Pós-graduação em História Social da Universidade Federal do Rio de Janeiro (Rodrigues, 2008).

${ }^{2}$ Em análise das versões construídas pelos intelectuais sobre a proclamação da República no Brasil, Emília Viotti da Costa (1987) destaca que, após o embate entre republicanos e monarquistas, seria a vez de as teorias civilistas e militaristas influenciarem as interpretações da instauração da República: "Uma reivindicava para os militares, outra para os civis a glória do movimento. Uma condenava a atuação dos militares na política, considerando-a nociva. Outra acentuava os benefícios que tinham decorrido daquela intervenção" (p.280).

${ }^{3}$ A tradição historiográfica identificou e registrou três personagens marcantes nessa região, em especial no ponto que serviu de palco para o conflito do Contestado: o planalto catarinense. Eles foram chamados de monges devido às pregações, práticas de cura e hábitos simples. São eles: João Maria de Agostini, João Maria de Jesus e José Maria de Jesus. José Fraga Fachel (1995) afirma que o primeiro monge nasceu na região do Piemonte, Itália, e teria passado por Santa Catarina na década de 1840. Sobre os outros monges as informações não são precisas. O segundo seria proveniente de Buenos Aires ou da França; sua presença no planalto catarinense é destacada no contexto da Revolta Federalista de 1893. José Maria de Jesus, por sua vez, seria um desertor do Exército ou da Força Policial do Paraná; sua presença é registrada por volta de 1911. Morreu em outubro de 1912 durante o primeiro combate travado no vilarejo chamado Irani, região disputada por Paraná e Santa Catarina. As pesquisas recentes (Karsburg, 2012) têm trabalhado com a hipótese de que o planalto meridional foi habitado por muitos 'monges', todos identificados como João Maria. Nesse sentido, João Maria é antes uma figura da hagiografia e não personagem real. 


\begin{abstract}
${ }^{4}$ Trata-se da Revolta de Juazeiro, liderada pelo padre Cícero e Floro Bartolomeu contra o governo do coronel Franco Rabello. Esse oficial assumiu a presidência do estado do Ceará após conturbada disputa eleitoral que derrubou a oligarquia Acioli. Para mais informações, ver Ralph Della Cava, 1976.

${ }^{5}$ Há evidências de que alguns oficiais ilustrados se dirigiram para o Contestado com a função primordial de redigir a história da atuação do Exército nesse conflito (Rodrigues, 2008).

${ }^{6}$ Por historiadores de farda entendo os oficiais do Exército com vocação para pesquisa que inseriram a história da corporação militar no cenário da história do Brasil. A categoria foi definida e analisada mais detidamente em minha tese de doutorado (Rodrigues, 2008, p.69-155). Entre os historiadores de farda do Contestado vale registrar os nomes de Antonio Alves Cerqueira, Ezequiel Antunes de Oliveira, José Octaviano Pinto Soares, Herculano Teixeira d'Assumpção, José Vieira da Rosa e Dermeval Peixoto.

${ }^{7}$ Lançado em 1902, Os sertões (Cunha, 2001) atingiu a corporação militar ao criticar o despreparo das forças armadas em termos bélicos e ideológicos e denunciar as ações bárbaras cometidas contra os conselheiristas, tais como degolas e comércio de crianças.

${ }^{8}$ As legendas das fotos desse álbum assim como das fotografias de guerra na imprensa foram reproduzidas neste texto tal como aparecem nos documentos, portanto, será comum o tratamento de fanáticos e bandidos conferido aos sertanejos do Contestado.

${ }^{9}$ A lista completa dos nomes pode ser encontrada em Capella (1985, p.235-236).

${ }^{10}$ Soares já publicava matérias sobre a intervenção do Exército no Contestado no momento do conflito. Essas matérias deram origem ao livro publicado em 1920, portanto, as ideias veiculadas são contemporâneas
\end{abstract} ao momento de atuação de Bilac e dos defensores da modernização do Exército.

\title{
REFERÊNCIAS
}

ÁLBUM...

Álbum da Campanha do Contestado. 87 fot. p\&b 12 x 16,5 cm. Seção de Iconografia. Fundo da Campanha do Contestado (cpco); 3.4 .22 (Arquivo Histórico do Exército). 1914-1915.

ANDRADE, Joaquim Marçal Ferreira de. A fotografia de guerra e o episódio de Canudos ou a documentação como alvo. Cadernos de fotografia brasileira. Rio de Janeiro, p.238-269. 2002.

BEATTIE, Peter M.

Tributo de sangue: Exército, honra, raça e nação no Brasil, 1864-1945. Trad., Fábio Duarte Joly. São Paulo: Edusp. 2009.

BILAC, Olavo.

A defesa nacional (discursos). Rio de Janeiro: Biblioteca do Exército. 1965.

CAPELLA, Leila Maria Corrêa. As malhas de aço no tecido social: a revista "A Defesa Nacional" e o Serviço Militar Obrigatório. Dissertação (Mestrado) Programa de Pós-graduação em História, Universidade Federal Fluminense, Niterói. 1985.

CARVALHO, José Murilo de.

As forças armadas na Primeira República: o poder desestabilizador. In: Fausto, Boris (Org.). História geral da civilização brasileira. t.3, v.2, São Paulo: Difel. 1974.

COSTA, Emília Viotti.

Da Monarquia à República: momentos decisivos. São Paulo: Brasiliense. 1987.
CUNHA, Euclides da.

Os sertões: campanha de Canudos. São Paulo: Ateliê Editorial. 2001.

D’ALESSIO, Vito (Org.).

Claro Jansson: o fotógrafo viajante. São Paulo: Dialeto Latin American Documentary. 2003.

DELLA CAVA, Ralph.

Milagre em Juazeiro. Rio de Janeiro: Paz e Terra. 1976.

DIACON, Tod.

Milenarian vision, capitalist reality: Brazil's Contestado rebellion, 1912-1916. Durham, N.C.: Duke University Press. 1991.

DIMAS, Antônio.

Bilac: o jornalista. 3v. São Paulo: Edusp. 2006.

DIVERSOS ASPECTOS.

Fon-Fon, Rio de Janeiro. Fon-Fon no

Contestado, ano 9, n.6, p.22. 6 fev. 1915.

DOUS CHEFES...

Dous chefes de bando. Fon-Fon, Rio de Janeiro. Fon-Fon no Contestado, ano 9, n.5, p.33. 29 jan. 1915.

FACHEL, José Fraga.

Monge João Maria: recusa dos excluídos. Porto Alegre: Editora da UFRGS; /Florianópolis: Editora da UFSC. 1995.

FLUSSER, Vilém.

Filosofia da caixa preta: ensaios para uma futura filosofia da fotografia. Rio de Janeiro: Relume Dumará. 2002. 
FON-FON...

Fon-Fon no Contestado. Fon-Fon, Rio de Janeiro, ano 9, n.7, p.48. 13 fev. 1915.

KARSBURG, Alexandre.

O eremita do novo mundo. A trajetória de um eremita italiano na América do século XIX. Tese (Doutorado) - Programa de Pós-Graduação em História Social, Universidade Federal do Rio de Janeiro, Rio de Janeiro. 2012.

LIMA, Nísia Trindade.

Um sertão chamado Brasil: intelectuais e representações geográficas da identidade nacional. Rio de Janeiro: Revan. 1999.

MACIEL, Laura Antunes.

A nação por um fio: caminhos, práticas e imagens da "Comissão Rondon". São Paulo: Educ. 1998.

MAUAD, Ana Maria.

"O olho da história": análise da imagem fotográfica na construção de uma memória sobre o conflito de Canudos. Acervo, Rio de Janeiro, v.6, n.12, p.25-40. 1993.

MONTEIRO, Duglas Teixeira.

Os errantes do novo século: um estudo sobre o surto milenarista do Contestado. São Paulo: Duas Cidades. 1974.

MORETTI, Dorothy Janson.

Alguns instantâneos da vida de Claro Gustavo Jansson. In: Machado, Paulo Pinheiro; Espig, Márcia Janete (Org.). A guerra santa revisitada: novos estudos sobre o movimento do

Contestado. Florianópolis: EdUFSC, p.295-298. 2008
OLIVEIRA, Lucia Lippi.

A questão nacional na Primeira República. São Paulo: Brasiliense. 1990.

PEIXOTO, Dermeval.

A Campanha do Contestado. Curitiba: Fundação Cultural. (Coleção Farol do Saber, 3v.). 1995.

RODRIGUES, Rogério Rosa.

Veredas de um grande sertão. A Guerra do Contestado e a modernização do Exército brasileiro. Tese (Doutorado) - Programa de Pósgraduação em História Social, Universidade Federal do Rio de Janeiro, Rio de Janeiro. 2008.

SILVA, Rosângela Cavalazzi da.

Terras públicas e particulares: o impacto do capital estrangeiro sobre a institucionalização da propriedade privada (um estudo sobre a Brazil Railway Company no meio-oeste catarinense). Dissertação (Mestrado) Programa de Pós-graduação em Direito, Universidade Federal de Santa Catarina, Florianópolis. 1983.

SOARES, José Octaviano Pinto.

Apontamentos para a história: o Contestado. Porto Alegre: Oficinas Gráficas do Instituto de Eletrotécnica da Escola de Engenharia de Porto Alegre: s.n. 1920.

SONTAG, Susan.

Sobre fotografia. São Paulo: Companhia das Letras. 2004.

TACCA, Fernando de.

A imagética da Comissão Rondon. Campinas: Papirus. 2001.

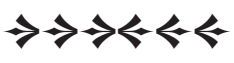

